\title{
Fantasia e Teorias da Sedução em Freud e em Laplanche ${ }^{1}$
}

\author{
Lea Silveira Sales ${ }^{2}$ \\ Universidade Federal de São Carlos
}

\begin{abstract}
RESUMO - Os elementos fornecidos por Freud ao teorizar sobre as fantasias inevitavelmente conduzem a dúvidas e obscuridade. O objetivo do presente artigo foi percorrer as indagações decorrentes do tratamento freudiano do problema, tomando como base, além de seus próprios textos, o desenvolvimento sugerido por Pontalis e, principalmente, por Laplanche na construção de sua teoria da sedução generalizada, que se desdobra especialmente nos conceitos significante enigmático e objetofonte da pulsão. Com isso, Laplanche torna possível a argumentação de que a sedução não é apenas um acontecimento pontual, mas aquilo que permite pensar as origens do sujeito psíquico no que ele possui de universal.
\end{abstract}

Palavras-chave: Psicanálise; fantasia; sedução; Freud; Laplanche.

\section{Fantasy and Theories of Seduction in Freud and in Laplanche}

\begin{abstract}
The elements provided by Freud when theorizing about fantasies inevitably lead to doubts and obscurity. The aim of the present paper is to build a reflection on the questions arising out of the Freudian treatment to the problem, following his own articles and the development suggested by Pontalis and especially by Laplanche in the construction of his theory of generalized seduction which has as central concepts the enigmatical signifier and the source-object of the drive. Thus Laplanche makes possible the argumentation that the seduction is not a punctual event but an element which allows thinking the origins of the psychic subject in his universality.
\end{abstract}

Key words: Psychoanalyis; fantasy; seduction; Freud; Laplanche.

\section{Elementos do conceito de fantasia na teoria freudiana}

Ao percorrerem a obra de Freud buscando o que ela teria a dizer sobre o conceito em questão, Laplanche e Pontalis (1964/1988) perceberam que as fantasias aí se situam exatamente na oposição entre o subjetivo e o objetivo, entre o princípio do prazer - que reza a busca da satisfação por meio da ilusão - e o princípio da realidade - que, mediante o sistema perceptivo, fala das relações do sujeito com o mundo exterior e com as restrições impostas por este. Assim, é justamente a introdução do princípio de realidade que induz à formação de uma nova atividade do pensamento - a produção de fantasias -, atividade submetida ao princípio do prazer e distanciada das exigências do mundo externo.

Freud explica essa visão da gênese das fantasias em uma das conferências introdutórias intitulada Os caminhos da formação de sintoma (1917/1986). Aí, ele afirma que, na fantasia, o sujeito perpetua uma certa sensação de liberdade à qual teve que renunciar em função da realidade. O homem, ser

1 Este trabalho originalmente compôs a monografia de graduação "O olhar e o lobo: pensando a pulsão escópica nas fantasias originárias” desenvolvida sob a orientação da Profa. Dra. Analuiza Mendes Pinto Nogueira (Curso de Psicologia, Universidade Federal do Ceará). Após sofrer modificações, foi apresentado com o título "O conceito de fantasia em Freud e as teorias da sedução" no IX Encontro Nacional de Filosofia da Associação Nacional de Pós-Graduação em Filosofia (ANPOF) - realizado nos dias 03 a 08 de outubro de 2000 em Poços de Caldas, MG.

2 Endereço: Rua Rafael de Abreu Sampaio Vidal, n ${ }^{\circ} 2729$, ap.: 64, Vila Costa do Sol, São Carlos, SP. CEP: 13566-220.

E-mail: lea_silveira@uol.com.br racional e dotado da capacidade de controlar suas vontades, permanece, com a atividade da fantasia, o animal que busca o prazer:

[...] o eu do homem é educado pouco a pouco para apreciar a realidade externa e para obedecer ao princípio de realidade por influência da pressão exterior. Nesse processo tem que renunciar de maneira transitória ou permanente a diversos objetos e metas para os quais está voltada sua busca de prazernão só sexual. Mas sempre é difícil para o homem a renúncia ao prazer; não a leva a cabo sem algum tipo de compensação. Por isso reservou uma atividade da alma em que concede a todas estas fontes de prazer e a estas vias abandonadas uma sobrevivência, uma forma de existência que as emancipa do requisito da realidade e do que chamamos 'exame de realidade’. (Freud, 1917/1986, p. 339)

O sujeito, com seu mundo de exigências pulsionais, depara-se com um outro mundo - diferenciado de seu próprio corpo - que não satisfaz aquelas exigências e desse choque nasceria a fantasia como construção do inconsciente?

Decerto que o problema colocado por Freud não cabe inteiro nesta explicação. Ele afirma que é da pulsão que surge a exigência de construção da fantasia; no entanto, isto não responde à constatação, na clínica, da repetição de cenas com o mesmo conteúdo. Freud destaca freqüentemente a ocorrência de três fantasias: a observação do coito dos pais, a sedução por um adulto e a ameaça de ser castrado - menos freqüentemente, ele acrescenta a este grupo a fantasia de retorno ao útero materno. ${ }^{1}$ Sobre tais eventos, escreve que, mesmo sem encontrar apoio em cenas reais, eles "[...] se estabelecem a partir de indícios e são completados mediante a 
fantasia" (Freud, 1917/1986, p.338), ou seja, embora a fantasia não seja "real", seus diferentes componentes estiveram presentes na infância do sujeito².

Freud postula que a recorrência dessas fantasias como um fato necessário e sempre presente na análise deve-se a uma determinação fillogenética. ${ }^{3}$ Em tempos primevos, os seres humanos teriam realmente passado por experiências desta ordem (observação do coito dos pais, sedução e castração) e a inscrição psíquica de tais experiências nos teria sido transmitida por nossos ancestrais. Quando, então, a criança não pudesse dar conta de elaborar as questões de seus movimentos pulsionais, buscaria, naqueles acontecimentos pré-históricos, elementos que favorecessem a construção de suas fantasias:

Nelas [nas fantasias], o indivíduo remete sua própria experiência à experiência pré-histórica, nos pontos em que a primeira tenha sido demasiado rudimentar. Parece-me muito possível que tudo o que hoje nos é contado na análise como fantasia - a sedução infantil, a excitação sexual suscitada pela observação do coito dos pais, ameaça de castração (ou melhor, a castração) - foi uma vez realidade nos tempos originários da família humana, e que a criança, ao fantasiar, não faz mais do que preencher as lacunas da verdade individual com uma verdade pré-histórica. (Freud, 1917/1986, p. 338)

A criança se utiliza dos acontecimentos na vida de seus ancestrais para suprimir os vazios da verdade individual. "Freud constatou a presença nos sujeitos de 'fantasias típicas'; concluiu disto que sua forma é inevitável, que decorre de uma 'psicologia coletiva', na qual a experiência individual deve se inscrever." (Huot, 1987/1991, p. 146) Enfim, as cenas prototípicas de observação do coito dos pais, de ser seduzido na infância e de ser ameaçado com a castração constituiriam uma herança filogenética. O que fora realidade de fato transformara-se em realidade psíquica.

Mas, em que momentos da vida, a criança precisaria recorrer a esta verdade anterior à sua própria existência? Em Inibição, sintoma e angústia (Freud, 1926/1986), são relatadas algumas situações, por assim dizer, críticas, situações de perigo, pelas quais o sujeito passa necessariamente e que têm, cada uma, um determinante apropriado de angústia. Primeiramente, há uma fase da vida em que o principal interesse da criança é ter sempre o carinho das pessoas das quais

1 Em uma nota de 1920 aos Três Ensaios de Teoria Sexual (1905/1986), por exemplo, Freud apresenta as quatro cenas: "Entre as fantasias sexuais do período da puberdade sobressaem algumas que se singularizam por sua universalidade e sua considerável independência do que foi vivenciado pelo indivíduo. Assim, as fantasias de escutar as relações sexuais dos pais, da sedução pelas pessoas amadas, da ameaça de castração, aquelas cujo conteúdo é a permanência no ventre materno [...]." (p. 206) Neste momento, ele ainda acrescenta a fantasia da "novela familiar", a qual remete ao artigo A novela familiar dos neuróticos (1909/1986).

2 Para Huot (1987/1991), é neste momento da obra de Freud que reside propriamente o nascimento da psicanálise, momento em que se torna preciso realizar a análise da fantasia.

3 Já que não podia mais recorrer à sedução como fato individual tal como postulava em sua teoria da sedução. ela depende, interesse atrelado à questão do desamparo psíquico, ao perigo da perda do objeto e à imaturidade do organismo. Depois, surge o medo do pai, quando ela constata que este é um rival poderoso na disputa pelo amor da mãe e "[...] a angústia frente a seu castigo pode se exteriorizar, por reforço filogenético, como angústia de castração." (Freud, 1926/1986, p. 138) Finalmente, Freud cita o momento em que a criança começa a estabelecer relações sociais, quando "[...] a angústia frente ao supereu, a consciência moral, adquire um caráter necessário, e a ausência deste fator passa a ser a fonte de graves conflitos e perigos, etc." (Freud, 1926/ 1986, p. 138) No entanto, isto não quer dizer que tais situações de perigo tenham que existir separadamente; ao contrário, elas podem vir a entrar em ação ao mesmo tempo e o modo como isto acontece provavelmente estará em relação direta com as características da neurose.

Outro lugar onde Freud expõe mais alguns pensamentos sobre as fantasias é no artigo As fantasias histéricas e sua relação com a bissexualidade. Esse texto de 1908 já trazia a idéia de que um determinado sintoma não está ligado a apenas uma fantasia inconsciente, mas sim a um vasto número delas, principalmente quando a neurose tem lugar já há algum tempo. Tais fantasias, diz o autor, podem ter sido formadas no inconsciente sem jamais terem passado pela consciência, ou, "[...] - caso mais freqüente - foram uma vez fantasias conscientes, devaneios, e logo deliberadamente esquecidas, passaram para o inconsciente em virtude da 'repressão'." (Freud, 1909/1986, p.142)4 Vemos aqui, então, uma possibilidade de diferenciação entre dois tipos de fantasias: as fantasias essencialmente inconscientes - aquelas chamadas originárias ou primitivas - e os devaneios diurnos que passam primeiramente pela consciência, sendo que alguns de seus componentes são prontamente recalcados.

Obviamente, os elementos fornecidos por Freud para pensarmos a existência das fantasias nos conduzem a um mar de dúvidas e obscuridade. O que pensar da hipótese filogenética como instrumento explicativo para a repetição qualitativa de cenas nas fantasias originárias? A que questões estas "fantasias eleitas" - correspondentes a determinadas situações de perigo - vêm responder? Que sentido assume a diferenciação entre devaneios diurnos e fantasias originárias? Enfim, que lugar tais fantasias ocupam na constituição do sujeito e de seu desejo?

\section{Relação entre a fantasia e a teoria freudiana da sedução}

Sabemos que a fantasia surge como questão fundamental, como algo que se refere ao bojo da construção da teoria psicanalítica, no interior de uma relação íntima com a chamada teoria da sedução. Freud teria sido forçado, frente aos fatos e à sua auto-análise, a abandonar suas formulações acer-

4 Ainda sobre a questão das fantasias, o leitor pode consultar, na obra freudiana, o artigo $O$ criador literário e o fantasiar (1908/1986) e a conferência A feminilidade (1933/1986) 
ca da cena de sedução e a substituir a crença na realidade desta cena pela suposição de que a sedução seria uma construção, em termos de fantasia, do próprio sujeito, “[...] uma fantasia que é apenas o produto e a máscara das manifestações espontâneas da atividade sexual infantil."(Laplanche \& Pontalis, 1964/1988, p. 25). Para Laplanche e Pontalis (1964/ 1988), Freud estaria, desta forma, reconhecendo um "erro"; ele não relacionaria mais ao exterior o que seria uma questão interior. Estes autores entendem a formulação da teoria da sedução como uma tentativa de Freud no sentido de estabelecer um vínculo entre a sexualidade, o traumatismo e a defesa, isto é, de conferir exclusivamente à sexualidade a capacidade de induzir o processo de defesa, de produzir o recalque. Como isto acontece? As explicações freudianas àquela época (basicamente entre 1895 e 1897) baseavam-se na idéia central de que a ação traumática podia ser desmembrada em dois acontecimentos principais ocorridos em tempos distantes um do outro.

O primeiro destes acontecimentos seria a cena de sedução. No entanto, diante do comportamento sexual do adulto com relação à criança, esta não experimenta a excitação sexual e, portanto, não reage por meio da defesa. Desta forma, tal cena só seria sexual a partir do lugar do adulto perverso, visto que a criança "[...] não tem à sua disposição nem as condições somáticas da excitação, nem as representações para integrar o evento [...]" (Laplanche \& Pontalis, 1964/1988, p. 28). Dentro desta teoria, esta cena é caracterizada como sexual pré-sexual, ou seja, ela "[...] é sexual em si, embora não adquira qualquer significação sexual para o sujeito [...]." (Laplanche \& Pontalis, 1964/1988, p. 28)

Somente quando surge a segunda cena, é que a criança confere à primeira um sentido sexual. Esta segunda cena, que geralmente ocorre após a puberdade, não possui um caráter violento e nem é tão traumática quanto a primeira. Apenas suscita associações que remontam à lembrança da primeira cena e é aí que se encontra seu poder, pois a excitação sexual agora surpreende o eu exigindo que aquela lembrança seja recalcada.

É claro que sob este esquema das duas cenas jaz a suposição de uma inocência da criança, de uma ausência de sexualidade infantil. Laplanche vê que se trata aí de uma questão de defasagem.

A criança em questão [...] está sempre num estado chamado de imaturidade, de incapacidade, de insuficiência em relação ao que lhe acontece. [...] É esta defasagem que é o terreno do trauma. Podemos lançar a comparação com a neurose traumática do adulto, onde o essencial do trauma decorre do caráter fortuito do incidente, portanto, do fato de que o sujeito não está preparado para aquilo. Pois bem, o despreparo da criança é fundamentalmente sinônimo de sua Hilflosigkeit, ou, então, como se expressa aqui Freud, de um certo estado infantil das funções psíquicas, assim como do sistema sexual. (Laplanche, 1987/1992, p. 114)

Laplanche (1987/1992) chama este esquema de teoria da sedução restrita (visto que, a ela, contrapõe a sua própria teoria da sedução generalizada, a qual visitaremos adiante) e sabemos que Freud a abandonou precisamente durante o ano de 1897 quando expressou sua insatisfação em uma carta a seu amigo Fliess, afirmando que não acreditava mais em sua neurotica.

Os autores do trabalho sobre as fantasias, todavia, argumentam que nesta teoria reside um grande valor quanto à sexualidade humana. Primeiramente, por enunciar que " $[. .$. a sexualidade irrompe literalmente de fora para dentro, penetrando por efração num 'mundo da infância' que se supõe inocente [...]." (Laplanche \& Pontalis, 1964/1988, p. 29) Depois, por formular que, no segundo tempo, a emergência da sexualidade na puberdade é seguida da produção de desprazer, remetendo o sujeito àquele evento do exterior (cena de sedução) o qual foi internalizado na forma de um "corpo estranho" que age sobre o sujeito.

Colocavam-se então inevitavelmente duas alternativas: imputar ou ao externo ou ao interno a origem da sexualidade. Laplanche e Pontalis pensam que esta escolha não se faz necessária, pois

[...] todo o traumatismo provém simultaneamente do exterior e do interior. Do exterior, porquanto é do outro que a sexualidade chega ao sujeito, do interior, pois que jorra desse exterior interiorizado, dessa 'reminiscência' de que, segundo uma bela fórmula, sofrem os histéricos e na qual já reconhecemos a fantasia. (1964/1988, p. 31)

Contudo, na teoria da sedução, esses termos externo e interno têm um alcance restrito e bem delimitado: o primeiro refere-se ao evento, à cena de sedução, e o segundo ao endógeno e ao biológico.

Apesar disso, nesse texto, o que lhes interessa é pontuar a fundamental contribuição da teoria da sedução. Para eles, esta teoria constitui a única tentativa de Freud no sentido de estabelecer a relação do recalque com a sexualidade, além de ter considerado que esta relação diz mais respeito aos aspectos temporais do que ao "conteúdo" do acontecimento, e é precisamente isto o que faz da sexualidade "[...] o campo privilegiado de uma dialética entre o excesso e a falta de excitação, entre o cedo demais e o tarde demais do evento [...]." (Laplanche \& Pontalis, 1964/1988, p. 32) Este também será o ponto tomado como referência central por Laplanche quando da elaboração de sua teoria da sedução generalizada.

Já mencionamos o momento em que Freud "abandonou" a teoria da sedução e, naquela mesma carta, ele dissertara sobre os motivos da descrença: dificuldade para levar a fundo as análises, de chegar à origem, ao evento patogênico inicial; necessidade insustentável de pensar quaisquer adultos como perversos e, finalmente, o argumento de que " [...] no inconsciente não existe um signo de realidade, de modo que não se pode distinguir a verdade da ficção investida com afeto." (Freud, 1986, p. 301-302) ${ }^{5}$

5 Sobre a teoria da sedução e seu "abandono", podem ser consultados os seguintes trabalhos de Freud: Projeto de psicologia (1895/1986) [Parte II - Psicopatologia]; Novas observações sobre as neuropsicoses de defesa (1896/1986); A etiologia da histeria (1896/1986); Minhas te- 
Ora, a partir destas elaborações, Freud "redime" os adultos perversos passando a afirmar que a cena de sedução não possui correspondência na realidade externa - apesar de recorrer a alguns indícios dessa realidade - mas que se trata de uma construção fantasística, de uma "realidade psíquica". As lembranças relativas à cena não são enunciadas,

[...] não há saber do sujeito ao qual se possa recorrer no que lhes diz respeito, não há testemunhas que possam atestar as impressões do sujeito. Freud precisa utilizar aqui uma nova categoria conceitual: a fantasia. Esta está ligada à lembrança, à percepção de acontecimentos passados reais, mas não é inteligência, nem enunciação da lembrança. (Huot, 1987/1991, p. 68)

O problema que surge agora está exatamente relacionado à questão da origem da fantasia, esse "objeto psicanalítico por excelência” (Laplanche \& Pontalis, 1964/1988, p. 41,42). A alternativa - pensada por Jung - de encará-la como uma construção do adulto em análise sobre a sua própria infância não é endossada por Freud ${ }^{6}$, restando-lhe a idéia da predisposição hereditária. Na visão de Laplanche e Pontalis, tal solução coaduna-se com a tentativa de Freud de encontrar um real que sustente a ficção, além de indicar sua atitude relutante quanto a abandonar a positividade da teoria da sedução.

Se esta segunda possibilidade [a da hereditariedade] - sobre a qual Freud confessa tê-la sempre recalcado - recupera terreno, é porque, na verdade, a busca do evento originário redundou num impasse; mas também é porque Freud, nesse momento de confusão, não consegue desprender-se do que existe de positivo na teoria da sedução, para além do realismo do evento datável. Se o evento se esquiva, então o outro termo da alternativa - a constituição - é reabilitado. Pois se o real, numa de suas modalidades, falta e revela não passar de ficção, cumpre buscar alhures um real que sirva de alicerce para essa ficção. (Laplanche \& Pontalis, 1964/1988, p. 37)

Finalmente, esses autores ressaltam o fato de que, com o abandono da teoria da sedução, Freud considera a fantasia como uma expressão secundária da realidade de fatores biológicos da sexualidade infantil: "[...] a realidade é inteiramente transportada para uma sexualidade endógena cujas fantasias só poderiam ser uma eflorescência puramente imaginária." (Laplanche \& Pontalis, 1964/1988, p. 41)

\section{A proposta de Laplanche ${ }^{7}$}

No trabalho que realiza a respeito da ligação entre fantasia e sedução Laplanche propõe uma teoria da sedução ge-

ses sobre o papel da sexualidade na etiologia das neuroses (1904/ 1986); Apresentação autobiográfica (1924/1986); Novas conferências de introdução à psicanálise (1933/1986) [33ªconferência - A feminilidade].

6 Cf. por exemplo Freud (1918/1986).

7 O que interessa a essa proposta são as fantasias originárias. A partir do lugar a elas conferido é que se desenvolvem as soluções teóricas do autor. neralizada e isto exatamente para recuperar a positividade da teoria da sedução freudiana. Em Novos fundamentos para a psicanálise (1987/1992), este autor expõe sua visão sobre a sedução e defende que, na situação originária, ou seja, na origem da fantasia, trata-se do confronto do mundo da criança (esse ser que ainda não domina a fala) com o mundo adulto. É neste confronto e na emergência de sentimentos sexuais na criança que reside o caráter de universalidade das fantasias. Para Laplanche, são exatamente os fatos da existência concreta de pais e filhos e da emergência dessa sexualidade parcial na criança que conferem o aspecto de universalidade à construção das fantasias ${ }^{8}$.

Nessa cena, encontramos dois protagonistas: a criança e o adulto. Para a primeira, o lugar é o de um ser biopsíquico aberto ao mundo que pede ajuda ao estranho diante do transbordamento de sua excitação. Já o adulto atende a este pedido agindo a partir da dimensão de seu próprio inconsciente, a partir de seu próprio desconhecimento e de sua divisão. A questão originária pode ser definida, então, como a relação entre um adulto que sofre a sua própria clivagem - e que, por isso, é desviante de si mesmo - e uma criança que precisa adaptar-se ao mundo do adulto - e para isso depende enormemente dele - mas que só pode comportar-se de maneira frágil e imperfeita. Ora, o que poderia resultar desta relação senão a clivagem também da criança? Além disso, há o infantil do adulto: "[...] o adulto diante da criança será particularmente desviante, levado à operação falha, até o sintoma, nessa relação com esse outro ele mesmo, esse outro que ele mesmo foi. A criança diante dele faz apelo ao infantil nele." (Laplanche, 1987/1992, p. 11)

Nos Três ensaios, Freud, ao falar da relação da criança com a pessoa que a ela presta cuidados, afirma que esta atividade constitui para a primeira uma fonte incessante de geração do prazer sexual que nasce mediante a estimulação das zonas erógenas e pontua exatamente que tal pessoa (geralmente a mãe) exerce esta atividade já a partir de seus próprios sentimentos sexuais. Para ele, é evidente que a mãe, ao acariciar, beijar e embalar o bebê, está colocando este ser na posição de objeto sexual. Também ao discorrer sobre uma lembrança da infância de Leonardo da Vinci, Freud (1910/ 1986) comenta que o amor da mãe pelo seu filho é muito mais profundo quando este ainda é um bebê submetido aos seus cuidados e amamentado por ela. Trata-se de um apego bem diferente daquele experimentado pela mãe depois que a criança cresce. Seria mesmo da ordem de uma relação amorosa plenamente satisfatória capaz de gratificar tanto as necessidades físicas quanto os desejos dos seres envolvidos.

Diante dos termos da relação originária - um adulto cindido que carrega consigo seu infantil prenhe de sentido sexual mas que sobre isso não detém conhecimento e uma criança em estado de desajuda (Hilflosigkeit) que só pode recorrer a este adulto - Laplanche percebe que ela possui dois registros:

8 Vale frisar que o originário e o universal referem-se ao que está nas origens do ser humano. 
[...] uma relação vital, aberta, recíproca, que podemos perfeitamente dizer interativa, e uma relação onde está implicado o sexual, onde a interação não ocorre mais, pois a balança é desigual. [...] há um sedutor e um seduzido, um desviador e um desviado, conduzido para longe das vias naturais [...]. (1987/1992, p. 111)

Um papel fundamental é exercido aqui pela linguagem, visto que o mundo adulto do qual falamos é essencialmente um mundo de linguagem. Os pais respondem às demandas da criança a partir de uma estrutura lingüística específica e isto exerce uma função traumatizante na medida em que o ser que fala, por estar sujeito ao inconsciente, ignora o sentido daquilo que fala. Deste fato, Laplanche conclui que a relação adulto/criança é polarizada em atividade/passividade, sedutor/seduzido - pois o psiquismo do primeiro é, assim, mais rico que o da criança. No entanto "[...] esta riqueza do adulto é também sua enfermidade, sua clivagem em relação ao seu inconsciente.”(Laplanche, 1987/1992, p. 134)

Enfim, é deste confronto entre o adulto e a criança, fundamentado na linguagem, que se trata na sedução originária (lembremo-nos de que o sentido é sexual) e é por este caminho que ele sustenta a teoria da sedução generalizada. Nesta situação, todos os adultos são perversos na medida em que subscrevem um desvio em relação à ordem dita natural. "Por meio do termo sedução originária qualificamos, portanto, esta situação fundamental em que o adulto propõe à criança significantes não verbais assim como verbais, inclusive comportamentais, impregnados de significações sexuais inconscientes." (Laplanche, 1987/1992, p. 134)

Tais significantes põem a criança diante de enigmas e, portanto, Laplanche os denomina de significantes enigmáti$\cos$. Este conceito é fundamental para entender a teoria da sedução generalizada e, consequentemente, a noção de fantasia originária. $\mathrm{O}$ autor fornece o exemplo do seio. Sabe-se o quanto a mulher o investe sexualmente de forma inconsciente e Laplanche se pergunta se este investimento poderia ser ignorado pela criança:

Pode-se supor que esse investimento sexual, que pode ser considerado perverso no sentido dos Três ensaios de teoria sexual, não é percebido, suspeitado pelo bebê, como fonte deste obscuro questionamento: o que ele quer de mim, além de me aleitar e, no fim das contas, por que ele quer me aleitar? (1987/ 1992, p. 135)

Os enigmas sugerem a existência de alguma coisa que precisa ser compreendida pela criança, algo sobre o que ela é impelida a exercer domínio e teorizar. No entanto, esta coisa permanece como que em estado selvagem, implicando o trauma e o recalque, visto que o adulto não consegue explicá-los para si mesmo. Eles estão relacionados à questão da origem do sujeito, ao nascimento de um outro filho, à origem da sexualidade e à diferença entre os sexos. ${ }^{9}$

Assim, o termo sedução originária independe de ataques sexuais - a sedução é o enigma - e inclui nele mesmo as outras situações de sedução assim caracterizadas por seu

9 Cf. Laplanche \& Pontalis (1967/1992), verbete Fantasia. caráter enigmático (sedução dos cuidados maternos e sedução do "ataque" paterno, por exemplo). Segundo Laplanche, é na sedução originária que se encontra a essência de qualquer outra sedução por ser aí instaurada a polaridade atividade-passividade.

É a confrontação de um indivíduo cujas montagens somatopsíquicas situam-se predominantemente no nivel da necessidade, com significantes que emanam do adulto, ligados à satisfação dessas necessidades, mas veiculando consigo a potencialidade, a interrogação puramente potencial de outras mensagens sexuais. (Laplanche 1987/1992, p. 138)

Diante das mensagens sexuais - e da inadequação da linguagem infantil à linguagem do adulto -, a criança é chamada à tarefa de dominá-las e de simbolizá-las e dessa operação sobrarão como resto produtos inconscientes, os quais Laplanche denomina objetos-fontes da pulsão. Tal tarefa insere-se na ordem da impossibilidade não somente devido aos restos inconscientes, mas também à “[...] inadequação do adulto ao objeto-fonte que age nele mesmo." (Laplanche, $1987 / 1992$, p. 139)

$\mathrm{O}$ autor defende que essa forma de ver a teoria da sedução como algo mais amplo, inserido no cerne do confronto do mundo infantil com o mundo adulto, traz algumas implicações importantes. Não é mais necessário restringir sua aplicação a casos patológicos, já que, vista desta forma, a teoria da sedução refere-se à chegada de uma criança em um mundo habitado pela linguagem; ela descarta a necessidade de se procurar na biologia e na filogênese explicações para as fantasias e busca formular uma estrutura para o funcionamento do aparelho psíquico. Além disso, estabelece uma forma de pensar a existência do inconsciente, seu efeito de pulsão, bem como as possibilidades e limites do tratamento. Embora não tenhamos a intenção de discorrer sobre estas implicações, registramos que o redimensionamento teórico sugerido por Laplanche não se restringe à sedução em si, mas põe em pauta um modo diferente de questionar os conflitos pulsionais.

Resta-nos discorrer sobre uma última questão: a distinção entre devaneio diurno e fantasia inconsciente. Laplanche e Pontalis consideram que sustentar tal distinção é não compreender o problema na forma em que ele foi posto pelo próprio Freud. Eles colocam que manter a unidade do conjunto - ou seja, perceber que um mesmo conteúdo pode manifestar-se tanto no sistema inconsciente quanto no pré-consciente/consciente, perceber que as fantasias estão ligadas simultaneamente ao desejo inconsciente e à elaboração secundária - significa privilegiar o conceito de fantasia como algo que pode servir de instrumento para a apreensão do processo de recalque e de retorno do recalcado, ou seja, do processo de passagem entre os vários sistemas psíquicos. "Parece pois que a problemática freudiana da fantasia não só não autoriza uma distinção de natureza entre fantasia inconsciente e fantasia consciente, como visa, sobretudo, assinalar as analogias, as relações estreitas, as passagens entre elas [...].” (Laplanche \& Pontalis, 1967/1992, p. 172) Segundo esse ponto de vista, o que se quer é ressaltar que aqueles dois tipos de fantasia estão em íntima comunicação e constituiri- 
am um só e mesmo conjunto. A despeito de diferenças relacionadas ao grau de acesso à consciência, à forma atuada ou representada e ao fato de serem ou não projetadas sobre outras pessoas, as fantasias se referem, em última instância, a uma mesma estrutura que funciona como uma espécie de ponto organizador da vida psíquica, para o qual os autores sugerem o nome de "fantasística".

Para concluir, podemos afirmar que a visão de Laplanche baseada na noção de teoria da sedução generalizada - ou seja, a sedução não é um acontecimento pontual mas aquilo mesmo que dá conta de pensar as origens de um sujeito psíquico no que ele tem de universal - essa visão, na medida em que se desdobra especialmente nos conceitos de significante enigmático e de objeto-fonte da pulsão, nos permite recolocar, ressignificar o problema da fantasia originária tal como sugerido por Freud, favorecendo uma saída para a oposição subjetivo/objetivo, fantasia/realidade. A fantasia, segundo esse ponto de vista, não se restringe a uma interioridade psíquica herdada da história da humanidade mas se refere ao fato objetivo da sedução.

\section{Referências}

Freud, S. (1986) Proyecto de psicología. Em Obras completas. Buenos Aires: Amorrortu Editores, vol 1, p. 323-446. (Trabalho original publicado em 1950 e escrito em 1895)

Freud, S. (1986) La etiología de la histeria. Em Obras completas. Buenos Aires: Amorrortu Editores, vol 3, p. 185-218. (Trabalho original publicado em 1896)

Freud, S. (1986) Nuevas puntualizaciones sobre las neuropsicoses de defensa. Em Obras completas. Buenos Aires: Amorrortu Editores, vol 3, p. 157-184. (Trabalho original publicado em 1896)

Freud, S. (1986) Fragmentos de la correspondencia con Fliess. Carta 69, 21 de setiembre de 1897. Obras completas. Buenos Aires: Amorrortu Editores, vol 1, p. 301-302.

Freud, S. (1986) Mis tesis sobre el papel de la sexualidad en la etiología de las neurosis. Em Obras completas. Buenos Aires: Amorrortu Editores, vol 7, p. 259-272. (Trabalho original publicado em 1905)

Freud, S. (1986) Tres ensayos de teoría sexual. Em Obras completas. Buenos Aires: Amorrortu Editores, vol 7, p. 109-224. (Trabalho original publicado em 1905)
Freud, S. (1986) El creador literario y el fantaseo. Em Obras completas. Buenos Aires: Amorrortu Editores, vol 9, p. 123136. (Trabalho original publicado em 1907)

Freud, S. (1986) Las fantasías histéricas y su relación con la bisexualidad. Em Obras completas. Buenos Aires: Amorrortu Editores, vol 9, p. 137-148 (Trabalho original publicado em 1908)

Freud, S. (1986) La novela familiar de los neuróticos. Em Obras completas. Buenos Aires: Amorrortu Editores, vol 9, p. 213220. (Trabalho original publicado em 1908)

Freud, S. (1986) Un recuerdo infantil de Leonardo da Vinci. Em Obras completas. Buenos Aires: Amorrortu Editores, vol 11, p. 53-128. (Trabalho original publicado em 1910)

Freud, S. (1986) Conferencias de introducción al psicoanálisis. Los caminos de la formación de síntoma ( $23^{\mathrm{a}}$ conferência). Em Obras completas. Buenos Aires: Amorrortu Editores, vol 16, p. 326343. (Trabalho original publicado em 1917)

Freud, S. (1986) De la historia de una neurosis infantil. Em Obras completas. Buenos Aires: Amorrortu Editores, vol 17, p. 1-112. (Trabalho original publicado em 1918)

Freud, S. (1986) Presantación autobiográfica. Em Obras completas. Buenos Aires: Amorrortu Editores, vol 20, p. 1-70. (Trabalho original publicado em 1924)

Freud, S. (1986) Inibición, síntoma y angustia. Em Obras completas. Buenos Aires: Amorrortu Editores, vol 20, p. 71-164. (Trabalho original publicado em 1925)

Freud, S. (1986) Nuevas conferencias de introducción al psicanálisis. La feminidad ( $33^{a}$ conferência). Em Obras completas. Buenos Aires: Amorrortu Editores, vol 22, p. 104-125. (Trabalho original publicado em 1933)

Huot, H. (1991) Do Sujeito à Imagem: Uma História do Olho em Freud. São Paulo: Escuta. (Trabalho original publicado em 1987)

Laplanche, J. (1992) Novos Fundamentos para a Psicanálise. São Paulo: Martins Fontes. (Trabalho original publicado em 1987)

Laplanche, J. \& Pontalis, J.-B. (1992) Vocabulário da Psicanálise. São Paulo: Martins Fontes. (Trabalho original publicado em 1967)

Laplanche, J. \& Pontalis, J.-B. (1988) Fantasia Originária, Fantasias das Origens, Origens da Fantasia. Rio de Janeiro: Jorge Zahar Editor. (Trabalho original publicado em 1964) 